\title{
CORRESPONDENGE
}

\section{The Diagnosis and Treatment of Primary Hyperaldosteronism in Germany-Results on 555 Patients From the German Conn Registry}

by Dr. med. Caroline Schirpenbach, Felix Segmiller, PD Dr. med. Sven Diederich, Dr. med. Stefanie Hahner, Prof. Dr. med. Reinhard Lorenz, Prof. Dr. med. Lars C. Rump, Prof. Dr. med. Jochen Seufert, PD Dr. med. Marcus Quinkler Dr. med. Martin Bidlingmaier in volume 18/2009

\section{Doubts}

If 5 centers captured 555 patients with Conn's syndrome over 16 years-22 patients per year and per center-then I have serious doubts whether " $5 \%$ to $12 \%$ of patients with high blood pressure"- that is, 1.2 million people in Germany-have Conn's syndrome. In 20 years working as a specialist in internal medicine I have treated many patients with treatment resistant hypertension. I have often ordered tests for aldosterone and renin, which have almost never given any indication of Conn's syndrome. Are there any epidemiological data that prove the frequency of Conn's syndrome in a more convincing manner than the estimates mentioned in the article?

DOl: 10.3238/arztebl.2009.0692a

\section{REFERENCES}

1. Schirpenbach C, Segmiller F, Diederich S, et al.: The diagnosis and treatment of primary hyperaldosteronism in Germany-results on 555 patients from the German Conn Registry. Dtsch Arztebl Int 2009; 106(18): 305-11.

Dr. med. Jürgen Sindermann

Neuburger Str. 34

86167 Augsburg, Germany

jcsindermann@t-online.de

\section{In Reply:}

Dr Jürgen Sindermann's letter provides us with an opportunity to go into greater detail about the prevalence of Conn's syndrome. The detection rate of primary hyperaldosteronism depends on two factors: firstly, the biochemical screening strategy, and secondly, the pretest probability in the particular cohort under investigation. If in one practice's cohort of hypertension patients only hypokalemic hypertension patients are examined for Conn's syndrome, the detection rate, relative to all hypertension patients, is less than $1 \%, 1-4 \%$ in specialized hypertension outpatient clinics. If, however, all hypertension patients-independently of their hypokalemic status - are screened by using the aldosterone-renin ratio, the detection rate is 4-13\%. The prevalence of Conn's syndrome increases with the severity of the hypertension. The prevalence in patients with grade 1 hypertension according to World Health Organization criteria is $2 \%$ and in patients with grade 3 hypertension, 13\% (1). The highest detection rate applies to therapy resistant hypertension, at $11-30 \%$ (2). Only few population based studies have been conducted to date. In the Framingham Offspring Cohort, a raised aldosterone-renin ratio was found in $8 \%$ of untreated hypertensive men. Subjects with the highest aldosterone-renin ratio in this study had a 53\% increased risk of developing hypertension. In sum, these data allow the conclusion that primary hyperaldosteronism is indeed much more common than hitherto assumed. The fact that the case numbers in the German Conn Registry do not reflect this is due to the conservative screening strategies employed by the participating centers. In most cases, the patients who were investigated were hypokalemic - this is in contrast to the international trend, where, increasingly, normokalemic variants of hyperaldosteronism are seen. The study structure of the registry (longitudinal cohort study) is fundamentally inappropriate as a basis for calculating prevalence rates in Germany.

DOI: 10.3238/arztebl.2009.0692b

\section{REFERENCES}

1. Mosso L, Carvajal C, González A, Barraza A, Avila F, Montero J, Huete A, Gederlini A, Fardella CE: Primary aldosteronism and hypertensive disease. Hypertension. 2003 Aug; 42(2): 161-5. Epub 2003 Jun 9.

2. Schirpenbach C, Reincke M: Epidemiologie und Ursachen der Therapie-resistenten Hypertonie. Internist 2009; 50(1): 7-16.

3. Schirpenbach C, Segmiller F, Diederich S, et al.: The diagnosis and treatment of primary hyperaldosteronism in Germany-results on 555 patients from the German Conn Registry. Dtsch Arztebl Int 2009; 106(18): 305-11.

Prof. Dr. med. Martin Reincke

Medizinische Klinik - Innenstadt

Klinikum der Universität München Ziemssenstr 1

80336 München, Germany

martin.reincke@med.uni-muenchen.de

\section{Conflict of interest statement}

The authors of both contributions declare that no conflict of interest exists according to the guidelines of the International Committee of Medical Journal Editors. 